\title{
A Comparative Study of Collective Self-Esteem and Perception of RacismAmong Cambodian Immigrants and French Quebecois
}

\author{
Sadeq Rahimi ${ }^{1, *}$, Cécile Rousseau ${ }^{2}$ \\ ${ }^{1}$ Medical Anthropology, University of Saskatchewan, 55 Campus Drive, Saskatoon, SK S7N 5B1 \\ ${ }^{2}$ Social and Transcultural Psychiatry, McGill University, 1033 Pine Ave W., Montreal, QC H3A 1A1 \\ *Corresponding Author: sadeq.rahimi@usask.ca
}

Copyright (c) 2013 Horizon Research Publishing All rights reserved.

\begin{abstract}
Collective self-esteem represents a potentially useful construct for understanding intergroup relations in multiethnic societies, but current literature reflects a gap in cross-cultural comparisons of this concept. This study was designed to compare expression of collective self-esteem and its relation to perception of self and others across two distinct cultural groups. Collective self-esteem, personal self-esteem and perception of racism were measured in two groups of 114 Cambodian immigrants and 94 Francophone Quebecois, each composed of adolescents and their parents. The magnitude of collective self-esteem, as well as its relation with personal self-esteem and perception of racism differed across groups. Further analyses highlighted cultural factors in the function and impact of collective self-esteem, while suggesting that cultural characteristics may change rapidly when groups experience considerable modifications in their social identity because of intergenerational shifts and because of minority-majority tensions.
\end{abstract}

Keywords Collective Self-Esteem, Racism, Minority, French,Cambodian, Quebec

\section{Identity and Self-Esteem}

Human and social sciences are increasingly occupied with passionate discussions of who, what, and how the human subject 'is', specifically with regard to the sociocultural environment that holds the person and shapes 'identity' (see e.g. Marsella, DeVos, \& Hsu, 1985; Markus \&Wurf, 1987; Markus \& Herzog, 1991; Porter and Washington, 1993; Whittaker, 1993; Banaji and Prentice, 1994; Ashmore and Jussim, 1997 for literature reviews in different areas). As Allund (1997) puts it, the developments of the past two decades have rendered a phenomenal search for identity and locatedness "the most central characteristic of our civilization's transformation" (p. 102). More recent trends in psychological literature reflect an increase in the importance attributed to identity as a social-psychological phenomenon, i.e., a psychological construct directly influenced by social and cultural variables. While it would be fair to argue that North American psychological literature reflects a long tradition of neglecting the 'collective' in favor of the 'individual,' the 'collective' has nonetheless been present at the margins of this tradition. The psychological theories of Baldwin (e.g., 1897), James (1983), or Jung (1936); as well as more sociologically informed thinkers like Cooley (1902) or Mead (1934), though somewhat distant from the mainstream scientific psychological literature, have nonetheless survived and influenced that mainstream. More importantly, the recent resurgence of interest in self and identity has been accompanied by an increased attention to the role of the collective, even within the North American psychological mainstream (see e.g., Markus and Wurf, 1987; Banaji\& Prentice, 1994; Taylor, 1997 for reviews).

A traditionally presumed relationship between the sense of identity and self-esteem becomes somewhat problematic in the transition from an individual-based to a collective-based model. Efforts to establish a one-to-one correlation between ethnic and racial group membership and self-esteem have generally proved problematic. For instance, while some researchers have found blacks and other ethno-cultural minorities in North America to have lower self-esteem than whites (e.g., Peterson and Ramirez, 1971; Chang, 1975; Knight, Kagan, Nelson \&Gumbiner, 1978; Osborne \&LeGett, 1982; Henkin\& Nguyen, 1984; Bowler, Rauch \&Schwarzer, 1986), others have found no such difference, or in fact the opposite (e.g. Porter \& Washington, 1979, 1989, 1993; Rovner, 1981; Wade, Thompson, Tashakkori, \&Valente, 1989; Tashakkori\& Thompson, 1991). Different theories have attempted to address the source of such contradictory findings. The notion of 'collective self-esteem', introduced to the American social psychological mainstream by Crocker and Luhtanen (Crocker \&Luhtanen, 1990; Luhtanen\& Crocker, 1992) as a construct distinct from and independent of personal self-esteem, provided a novel approach to addressing the controversy. Collective 
self-esteem has been conceived in the tradition of 'Social Identity Theory.' Social identity theory was developed by Henry Tajfel (Tajfel\& Turner, 1979; Tajfel, 1981) to address the growing need for more accurate models of psychological dynamics involved in the collective-individual relationship. Tajfel proposed social identity as, "that part of an individual's self-concept which derives from his knowledge of his membership in a social group (or groups) together with the value and emotional significance attached to that membership" (1981, p. 255). According to Tajfel, it was essential for an individual to strive to maintain not only a positive sense of personal identity, but also a positive sense of social identity (e.g. , Tajfel, 1981). Expanding on Tajfel's work, Crocker and Luhtanen (1990) suggested "collective self-esteem" as an indicator of individuals' positive evaluation of their social identity, in the same way that personal self-esteem has been understood as a positive evaluation of one's personal identity. Collective self-esteem was then rapidly put to use by social psychology researchers as a useful construct for investigating the psychological impact and dimensions of group membership. The construct collective self-esteem, however, has been mostly used to address individual-level phenomena such as social behavior or mental health. Despite significant early findings that indicated ethnic or cultural groups can have distinctly different levels of collective self-esteem (e.g. Crocker, Luhtanen, Blaine, and Broadnaz, 1994), few studies addressed the potentially important implications associated with cross-cultural differences in magnitude or effects of collective self-esteem as a culture-specific characteristic (see e.g. Ahlering, 2003). In this study we adopted the notion of collective self-esteem proposed by Crocker and Luhtanen (1990) as our working construct to address such differences, and we used the Collective Self-Esteem Scale developed by Luhtanen and Crocker (1992) to quantify the concept in question.

\section{Self-Esteem, and Perception of 'the Other'}

Collective Self-Esteem has been demonstrated to correlate only moderately with Personal Self-Esteem $(\underline{r}=.35$, personal self-esteem measured by Rosenberg's (1965) Personal Self-Esteem Scale), and thus empirically distinct from it (see Luhtanen\& Crocker, 1992; Verkuyten\& Masson, 1995). Studies have also found differential effects of collective and personal self-esteem on attitudinal and behavioral reactions, supporting such a distinction. Rahimi and Fisher (2002) for example, reported a strong correlation between collective, but not personal, self-esteem, and construal of racism. Despite such empirical distinction between collective and personal self-esteem, however, findings do indicate the possibility of parallel patterns existing in the dynamics ruling the effects and implications of the two constructs. Self- and group-enhancing cognitive distortions of the environment, patterns of reaction to self- or group-targeting threats to identity, and ingroup favoritism are amongst the findings that imply structural similarities between these two constructs (see e.g. Crocker \&Luhtanen, 1990; Robins \& Foster, 1994; Verkuyten\& Masson, 1995 for more detail and examples of such patterns.). Luhtanen and Crocker (1992) and Robins and Foster (1994) found that, similar to the way personal self-esteem scores are known to predict responses to perceptions of threat to personal identity, collective self-esteem scores correlate closely with specific methods selected in confrontation with threats to collective identity. Verkuyten and Masson (1995) observed that minority group members who had higher collective self-esteem also displayed lower rates of outgroup rejection (ethnic prejudice). Proponents of Attribution Theory have long argued for connections between egocentric interpretation bias and self-esteem, suggesting that low personal self-esteem is generally conducive to more negative interpretations of others' behavior (see for example, Zuckerman Kernis, Guarnera, Murphy, \&Rappoport, 1983; Fenigstein, 1984; Kulik, Sledge, \& Mahler, 1986). Arguing for parallel dynamics, Rahimi and Fisher (2002) demonstrated that individuals with lower collective self-esteem are also more likely to interpret ambiguous behavior targeting their collective identity in negative terms. Given the body of evidence mentioned above, one may argue that collective identity and collective self-esteem are useful constructs in discussing intergroup relations in general, and more specifically, that collective self-esteem is a useful construct for explaining and understanding certain aspects of minority group psychology such as perception of the 'other'.

\section{The Cambodians and the French Quebecois}

This study was conceived to compare collective self-esteem and its psychological implications across two cultural groups: Francophone Quebecois and Cambodian refugees. According to existing ethnographic and psychological literature, these two groups possess distinct cultural features that would make a comparative discussion logically plausible. (See e.g. Donnely, 1989, Dorais, 1991, Hein, 1995, Rousseau et al. 2000, for more detailed accounts of cultural and psychological makeup of Cambodian immigrant communities in and compared to the North American context). Dorais (1991) analyzed the subtleties of the adaptation process for Indochinese refugees in Quebec, with an emphasis on the differences in 'community structures' of the two groups. Rousseau and colleagues (2000) reported an overview of the emotional and psychological aspects of the lives of young members of Cambodian refugee communities in Quebec, providing a distinct account of the cultural differences between the two populations. Donnely (1989) and Hein (1995) similarly studied the challenges and experiences arising from 
Cambodian cultural norms and structures in the process of adjusting to life in the United States, underlining the differences between North Americans and Cambodian refugees in family related norms, structures and expectations.

Based on the existing literature, differences were anticipated to exist between Quebecois and Cambodian populations in the relationship of the individual with the collective, specifically as reflected in personal and collective self-esteem. The two groups were also anticipated to show differences in their construal of others' attitudes towards self, specifically as indicated by differences in perception of racism. No cross-cultural comparisons of collective self-esteem and its effects as a culture-specific feature were found in literature at the time this project was carried out (though Crocker, Luhtanen, Blaine, and Broadnaz, 1994, or Ahlering, 2003, provide cross-cultural data for certain groups). It was therefore imperative to investigate the existence of distinct statistical populations with respect to collective self-esteem, before further cross-cultural comparisons could be justified. To our knowledge, this study has been the first to address that question.

\section{Hypotheses}

The research hypotheses were formulated as follows: (1) That the magnitude of scores obtained on the Collective Self-Esteem Scale is not the same across the two study populations. No directions were predicted for this difference, the objective was to merely investigate the possibility of differential magnitudes for collective self-esteem across cultural groups; (2) That the correlation between Collective and Personal Self-Esteem scores varies as a function of group membership across the study populations. Based on existing literature on social and ethnographic features of the two populations, it was predicted that Cambodian subjects would show stronger relationship between Collective and Personal Self-Esteem scores as compared to the Quebecois group; (3) That the magnitude of the relationship between Collective Self-Esteem and Personal Experience of Racism scores will vary as a function of social group membership.

\section{Method}

\subsection{Subjects}

This study was designed and conducted within the context of a longitudinal study conducted by Rousseau, et al. (Rousseau \&Drapeau, 1998, 1999). Initial selections had included the Cambodian teenage population from Montreal high schools, with the following criteria: enrolment in Grades 7 or 8, Cambodian origin, birth outside of Canada, and absence of physical or mental disabilities. Two years later Quebecois adolescents were recruited under similar criteria as a comparison group. The 208 subjects of this study consisted of 114 Cambodian and 94 Quebecois participants.
Tables 1 and 2 below display details of the sample's socio-demographic composition. Earlier studies have generally failed to find significant effects for gender on collective self-esteem scale (e.g. , Crocker \&Luhtanen, 1990; Luhtanen\& Crocker, 1992; Long, Spears, \&Manstead, 1994; Robins \& Foster, 1994). However, to control and document any possible gender effects, comparable numbers of male and female subjects were recruited. Half of the Cambodian sample and 54 percent of the Quebecois were female in our sample.

Table 1. Sample Composition: Ethnicity, Sex and Age Group

\begin{tabular}{|c|c|c|c|}
\hline & Cambodian & Quebecois & $\begin{array}{c}\text { Total } \\
\text { Sample }\end{array}$ \\
\hline Adolescents & 57 & 48 & 105 \\
\hline Parents & 57 & 46 & 103 \\
\hline Female & 61 & 51 & 112 \\
\hline Male & 53 & 43 & 96 \\
\hline Total & 114 & 94 & 208 \\
\hline
\end{tabular}

Table 2. Sociodemographic Profiles by Ethnic Group

\begin{tabular}{|c|c|c|}
\hline \multirow{2}{*}{} & \multicolumn{2}{|c|}{ Study Sample } \\
\cline { 2 - 3 } & Cambodian & Quebecois \\
\hline Adolescents & & \\
\hline M Age (yr.) & $17.5(\mathrm{SD}=1.0)$ & $17.2(\mathrm{SD}=1.0)$ \\
\hline \% Females & 42.1 & 45.8 \\
\hline Parents & 59.6 & 6.5 \\
\hline $\begin{array}{c}\text { \% Elementary or lower } \\
\text { education }\end{array}$ & 5.3 & 32.6 \\
\hline $\begin{array}{c}\text { \% University or higher } \\
\text { education }\end{array}$ & 75.4 & 17.4 \\
\hline \% Unemployed & & \\
\hline Household & 35.0 & 43.5 \\
\hline \% Single Parents & 21,053 & 45,308 \\
\hline Annual Income (\$Can) & 77.2 & 8.7 \\
\hline \% Low Income & & \\
\hline
\end{tabular}

\subsection{Variables and Scales}

\subsubsection{Collective Self-Esteem}

Collective self-esteem was operationally defined as the score obtained on the Public Collective Self-Esteem subscale of the "Collective Self-Esteem Scale" developed by Luhtanen and Crocker (1992). The 16-item Collective Self-Esteem Scale developed by Luhtanen and Crocker (1992) is composed of four subscales each of which addresses a distinct aspect of collective identity, as follows. Membership subscale: judgment of one's worth in relation to one's group, e.g. "I am a worthy member of the ethnic group I belong to." Private collective self-esteem subscale: one's private assessment of the value of one's group, as in, "I often feel that my ethnic group is not worthwhile." Public collective self-esteem subscale: one's judgment of the way others evaluate one's group, e.g., "In general, people think 
that the ethnic group I am a member of is unworthy." Finally, the Identity subscale addresses one's assessment of the significance of his/her group in his or her self-concept, as in, "My ethnic group is an important reflection of who I am."

The key conceptual question in this research was the way an individual's internal state affects his or her interpretation of the way others asses his or her group. However, unlike the question of self-esteem, where an individual's own perception of himself or herself is in question, here the question concerns the way one attributes attitudes towards his or her group to others, and the possible relationship such attribution might have with his or her further interpretation of the environment in terms of hostility towards the specific group he or she is a member of, in other words, racism. To target this notion, we operationally defined our variable in terms of the scores obtained on the Public Collective Self-Esteem subscale. Items were presented in alternating positive/negative order to reduce the risk of set responses. Subjects were required to respond to each item by selecting a number between 1 to 7 , where a choice of 1 corresponded to 'strongly disagree' and 7 to 'strongly agree'. Each subject could thus achieve a score between 4 to 28 . Luhtanen and Crocker (1992) have reported reliability test results for this subscale ranging from $\alpha=.78$ to $\alpha=.80$. In our study the Cronbach alpha was .73 for adolescents and .64 for parents, and across the cultures it was $\alpha=.72$ for the Cambodian and $\alpha=.70$ for the French Quebecois. The original scale was adjusted to fit this study, by addressing ethnic group membership instead of social groups in general. The alteration was done by replacing the generic words "group" or "groups" in the original scale by "ethnic group" in the adjusted version. According to Luhtanen and Crocker's (1992) report, the psychometric characteristics of the scale remained intact after such alteration.

\subsubsection{Personal Self-Esteem}

We operationally defined personal self-esteem as a subject's score on the 10-item Rosenberg Self-esteem Scale (Rosenberg, 1965). The 10 items of the Rosenberg scale address various aspects of self-perception and the individual's evaluation of that perception, such as "All in all, I am inclined to feel that I am a failure," or "I feel that I am a person of worth, at least on an equal plane with others." Participants were instructed to respond to each item by selecting from a Likert-style scale ranging between 1 and 4 , where 1 corresponds to 'strongly disagree' and 4 to 'strongly agree'. The range of scores for each subject on this scale was thus 10 to 40 . Negative and positive items referring to self-esteem are presented alternately in this scale, to reduce the danger of respondent set. Rosenberg (1989) reports a test-retest reliability of .93 , and an item scalability of .73 for the scale. Generally, the test-retest reliability of Rosenberg's Personal Self-Esteem Scale has been reported to be higher than .80 (see for example Rosenberg, 1965; Luhtanen\& Crocker, 1992). The Cronbach alpha of the Scale in our study was measured as .76 for parents and .79 for adolescents, and across groups it was $\alpha=.82$ for Cambodians and $\alpha=.71$ for the French Quebecois group. The Rosenberg Self-Esteem Scale is validated and often used in cross-cultural settings (Luhtanen\& Crocker, 1992). As mentioned earlier, the moderate correlation between collective and personal self-esteem scores has allowed empirical distinction between the two constructs (e.g. , Luhtanen\& Crocker, 1992; Verkuyten\& Masson, 1995). In the series of studies reported by Luhtanen\& Crocker (1992), for example, these correlations ranged from $\mathrm{r}=.26(\mathrm{p}<.001, \mathrm{~N}=178)$; to $\mathrm{r}=.38$ $(\mathrm{p}<.001, \mathrm{~N}=82)$.

\subsubsection{Experience of Racism}

Experience of racism was operationally defined as the magnitude of the subjects' score on The Experience of Racism Scale developed by Noh and his colleagues (see Noh, Beiser, Hou, \&Kaspar, 1999a; Noh, Beiser, Kaspar, Hou, \&Rummens, 1999b). The Experience of Racism Scale has been originally developed in the context of studies with Southeast Asian refugees in Canada and thus quite suitable for this study. The Scale is composed of eight items addressing various aspects of the experience of racism, such as "Have you ever been hit or handled roughly because of racism?" or "Have you ever been excluded or ignored because of racism?" Subjects were instructed to respond to each item by selecting a number from 0 to 4 , where 0 corresponded to 'Never' and 4 to 'Always'. A subject's score on Experience of Racism was calculated as the sum of scores on scale items, so each subject could have a score between zero and 32 on this Scale. Our reliability tests revealed Cronbach $\alpha=.89$ for parents and $\alpha=.77$ for adolescents, and across the cultures it was $\alpha=.82$ for the Cambodian group and $\alpha=.69$ for the French Quebecois.

\subsection{Procedure}

Both adolescents and their parents signed consent forms that described their participation and study procedure as well as the general objectives of the study.

All of the scales used in this study were translated into French and Khmer, and the accuracy of translated versions were tested by reverse translations which were then compared against the original scales in English. In addition to reverse translation, individual scale items and their possible ambiguities in French or Khmer translation were thoroughly discussed in training sessions held before and after a pilot test of the questionnaires.

Interviews were all conducted in subjects' homes by interviewers from their own ethnic group. Parents' interviews were conducted in the participants' mother tongue. Cambodian adolescents' interviewed were mostly in French, although they were interviewed by Khmer speakers and had the option to switch to Khmer where they wished so. The interviews were conducted over a period of five months. The average lengths of interviews were 93 minutes for adolescents and 52 minutes for parents.

\section{Results}




\subsection{Cross-Cultural Comparisons}

Cambodian adolescents had significantly higher scores on the Collective Self-Esteem Scale than did Quebecois adolescents (See table 3 for data discussed in this section). The adolescents' trend appeared reversed in the parents groups where the Quebecois score was of greater magnitude than the Cambodian parents' mean.

Table 3. Mean Scores of Cambodian and Quebecois Groups on Collective and Personal Self-Esteem, and Personal Experience of Racism

\begin{tabular}{|c|c|c|c|c|}
\hline & \multicolumn{2}{|c|}{ Cambodian } & \multicolumn{2}{c|}{ Quebecois } \\
\hline Adolescents & $\mathrm{M}$ & $\mathrm{SD}$ & $\mathrm{M}$ & $\mathrm{SD}$ \\
\hline Collective Self-Esteem & 21.1 & 3.8 & 18.6 & 4.9 \\
\hline Personal Self-Esteem & 30.3 & 4.3 & 32.4 & 3.4 \\
\hline $\begin{array}{c}\text { Personal Experience of } \\
\text { Racism }\end{array}$ & 11.5 & 4.1 & 12.4 & 3.7 \\
\hline Parents & $\mathrm{M}$ & $\mathrm{SD}$ & $\mathrm{M}$ & $\mathrm{SD}$ \\
\hline Collective Self-Esteem & 20.3 & 3.3 & 21.4 & 4.8 \\
\hline $\begin{array}{c}\text { Personal Self-Esteem } \\
\text { Personal Experience of } \\
\text { Racism }\end{array}$ & 27.8 & 2.8 & 33.4 & 3.4 \\
\hline \begin{tabular}{c} 
Pach \\
\hline
\end{tabular} & 12.1 & 6.5 & 10.8 & 3.4 \\
\hline
\end{tabular}

Cambodian adolescents had significantly lower Personal Self-Esteem scores than their Quebecois counterparts, a pattern similar to Cambodian parents who scored significantly lower on Personal Self-Esteem than Quebecois parents.

No statistically significant differences were found between the reported degrees of racism perceived by the Quebecois and Cambodian parents and adolescents. The mean magnitude of Experienced Racism for Quebecois adolescents was higher than that of the Cambodian adolescents. This trend was once again reversed in parents' case, where Cambodian parents' score was higher than the Quebecois.

\subsection{Cross-Generational Comparisons}

Cambodian adolescents and parents had comparable Collective Self-Esteem scores. This situation did not hold, however, within the Quebecois group, where adolescents' Collective Self-Esteem scores were significantly lower than that of their parents.

On the other hand, Cambodian parents and adolescents manifested significant differences on their Personal Self-Esteem scores. The adolescents' scores were significantly higher than their parents'. This relationship was different for the Quebecois, where parents and adolescents (both of whom had higher scores than their Cambodian counterparts, as mentioned earlier) did not show significant difference in their Personal Self-Esteem scores.

While Cambodian parents and adolescents did not show any significant differences in their Perception of Racism, a significant difference was to be found between the amount of racism experienced by Quebecois parents and adolescents. Quebecois adolescents reported higher racism targeting them than did their parents.

No differences were found between male and female populations on any of the scales, within any of the research groups. To further control for gender effects, partial correlations were calculated. Gender was not observed to have any significant effects on the results of the reported correlations.

\subsection{Correlations among Variables}

The correlation found between Personal and Collective Self-Esteem for the total sample was comparable to those reported originally by Luhtanen and Crocker (1992) followed by others (see above), at $\underline{r}=.204$, and $\underline{p}<.004$ (information discussed in this section is summarized in tables 4 and 5). The overall results showed a significant negative correlation between the Public subscale of Collective Self-Esteem and experience of racism within the research sample. Subjects' scores on the Rosenberg Personal Self-Esteem scale did not show any significant correlation with the subjects' experience of racism.

Table 4. Correlations among Collective and Personal Self-Esteem and Personal Experience of Racism in the Total Sample

\begin{tabular}{|c|c|c|}
\hline & 1. & \\
\hline 1. Collective Self Esteem & & \\
\hline 2. Personal Self-Esteem & $.20^{*}$ & \\
\hline 3. Personal Experience of Racism & $-.30^{\dagger}$ & -.10 \\
\hline
\end{tabular}

Table 5. Correlations among Collective and Personal Self-Esteem, and Personal Experience of Racism by Ethnic Group, Comparing Adolescents and Their Parents

\begin{tabular}{|c|c|c|c|c|}
\hline & \multicolumn{2}{|c|}{ Adolescents } & \multicolumn{2}{c|}{ Parents } \\
\cline { 2 - 5 } & Collective Self-Esteem & Personal Self-Esteem & Collective Self-Esteem & Personal Self-Esteem \\
\hline Cambodian & & & & \\
\hline $\begin{array}{c}\text { Collective } \\
\text { Self-Esteem }\end{array}$ & & $.44 \dagger$ & & $.42 \dagger$ \\
\hline Personal Experience of Racism & -.09 & $-.28^{*}$ & $-.42 \dagger$ & -.02 \\
\hline Quebecois & & & & .03 \\
\hline $\begin{array}{c}\text { Collective } \\
\text { Self-Esteem }\end{array}$ & & .16 & & .15 \\
\hline Personal Experience of Racism & $-.47 \dagger$ & -.12 & -.22 & \\
\hline
\end{tabular}


Once the total sample was broken into distinct cultural and generational groups, scores reflected interesting differences across those groups. A striking cross-cultural difference was found in the relationship between Collective Self-Esteem and Personal Self-Esteem. While for both Cambodian adolescents and parents significant correlations were found between Collective and Personal Self-Esteem scores, such correlations were not significant for Quebecois parents and adolescents.

Another intriguing finding was a reversal of direction in the relationship between Collective Self-Esteem and Personal Experience of Racism across the two ethnic groups. Within the Cambodian sample, a significant negative correlation was found between Collective Self-Esteem and Personal Experience of Racism of parents, which did not hold for adolescents. This relationship, however, was reversed for the Quebecois, whose scores showed a significant correlation between Collective Self-Esteem and Personal Experience of Racism of adolescents but not parents.

Apart from the Cambodian parents, for whom a negative correlation between Personal Self-Esteem and Experience of Racism was observed, no correlation was found between these two scores across the study groups.

\section{Discussion}

The results of this study generally supported our original hypotheses. The overall outcome replicated earliermixed-population findings, which may be taken as evidence that similar dynamics are at work within the general population. Given the differential trends across groups, of course, two further possibilities should be considered: either these results simply reflect what might be called a methodological artifact by confounding effects of group-specific trends, or indeed there is a certain globally applicable dynamic at work. More specifically controlled research would be required to prove or disprove either possibility.

Hypothesis one, that different groups could be distinguished according to their average scores on collective self-esteem, was supported by the results. Our results indicated that Quebecois parents, followed closely by Cambodian adolescents, had the highest Collective Self-Esteem scores of the four groups. Independent sample t tests showed that the Collective Self-Esteem of Cambodian adolescents was significantly higher than that of the Quebecois adolescents. Quebecois adolescents also had significantly lower Collective Self-Esteem scores than their parents. As will be discussed further, the Quebecois adolescents' lower Collective Self-Esteem as compared to the Cambodian adolescents, may bear interesting implications.

The second and third hypotheses, predicting differential relationships and associations for collective self-esteem across groups, were supported. The telling difference in the correlation of collective and personal self-esteem between the Quebecois and the Cambodian groups may be reflective of important structural and semantic differences in the way construct collective self-esteem is conceived in the two cultures. This finding aptly depicts a well-documented sense of collective cohesiveness in the Cambodian society as opposed to the oft cited contemporary decrease in such cohesion in Quebec. If it were true that the experiences of self and group have stronger affinities in Cambodian as compared to the Quebecois subjects, then one would only expect to find exactly what we have found.

Another cross-cultural difference lending further support to the third hypothesis was found in the relationships between collective self-esteem and experience of racism. In the Cambodian sample parents showed significant negative correlation between Collective Self-Esteem and Personal Experience of Racism and adolescents did not, but this relationship was reversed in the Quebecois groups. In addition to reflecting the basic point of our hypothesis that collective self-esteem and experience of racism can have differential relationships across groups, this pattern may also be depicting an interesting 'movement' in reverse directions within the two cultural groups. The movement metaphor may become more meaningful if this finding is juxtaposed with the trend of changes in Collective Self-Esteem scores discussed earlier. As can be seen in Fig. 1 below, a comparison of Collective Self-Esteem and its correlation with Experience of Racism shows that the two groups with highest scores on Collective Self-Esteem in this study show no significant correlation between Collective Self-Esteem and Experience of Racism. The other two groups with lower scores on Collective Self-Esteem, however, both indicate significant correlations between Collective Self-Esteem and Experience of Racism.

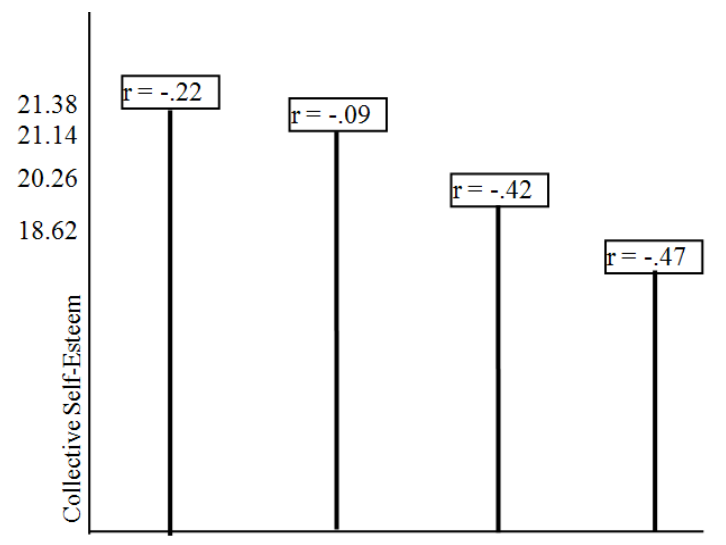

Figure 1. Correlation Trends Across Groups

This general pattern clearly supports earlier findings regarding the negative relationships between collective self-esteem and experience of racism. However, the detailed features may also indicate a more subtle point, namely that while lower Collective Self-Esteem scores may be more readily related to a defensive interpretation of the environment, such relationship does not necessarily hold 
where higher scores are reported. Such interpretation may point at an important issue concerning the limits to validity and/or usefulness of self-report scales such as the Collective Self-Esteem Scale. It may be the case, for instance, that those who self-report high scores on Collective Self-Esteem consist of two groups: those with true high collective self-esteem, and those with 'false' or defensively constructed high collective self-esteem (see for example Chodorkoff, 1954; Weinberger, Schwartz, \& Davidson, 1979; Shedler, Mayman, \&Manis, 1993; Greenwald \&Banaji, 1995, for discussion of similar concerns regarding self-report scales and personal self-esteem). This study was not specifically designed to address this phenomenon and thus a detailed discussion of that would be inappropriate here, but this finding should nonetheless be taken seriously, at least insofar as it highlights the need for future studies addressing the question of self-reported collective self-esteem.

Certain other trends reported above could have additional theoretical significance, as follows. As the results indicated, within the Cambodian group adolescents showed a lower correlation between Collective Self-Esteem and Experience of Racism than did their parents. This difference may be explicable in reference to at least two factors: the different social environments parents and their children are exposed to, and the different degrees of acculturation they might experience. Research has regularly shown that children and parents in immigrant and refugee families tend to manifest differential rates of acculturation (e.g. , Rueschenberg\&Buriel, 1995; Georgas, Berry, Shaw, \&Christakopoulou, 1996). If we understand acculturation as conducive to reducing social discomfort and thus alleviating tensions in host-minority social interactions, then the trend found above would seem only natural. Additionally, the environments to which immigrant and refugee parents are exposed tend to be generally different from those experienced by their children. While parents frequently have to face the less welcoming work environments of often unfair competition and at times explicit discrimination, their children may be more likely to find themselves in politically-correct multiethnic school environments which might be much less conducive to feeling discriminated against or singled out. Once again, if we accept the above scenario, it would only make sense to expect such different reactions from parents and children, to whom the implications of being part of a 'Cambodian' collectivity would thus be different.

There is of course another side to this coin, namely the opposite relation found between the scores of Quebecois parents and adolescents. Set within the above multiethnic school scenario, it appears logically sound to expect Quebecois adolescents to have a different understanding of the school environment. That is to say, the same multi ethnic environment that makes minority adolescents feel at home may 'on the other hand' make the otherwise majority group member Quebecois adolescent feel cornered by a sense of threat to his/her sense of collective identity (see Bibeau, Chan-Yip, Lock, Rousseau, Sterlin, \&Fleury, 1992, for more on this dynamic). At the workplace, however, the Quebecois parent may not necessarily have to face the same extent of threat from minority newcomers who, though may pose a certain amount of threat in the long run, are not necessarily qualified enough to cause 'clear and present' threat in most cases.

A number of precautions need to be taken into consideration when interpreting the results of this study. Primarily, the design of this study was correlational, so the results may not be taken to prove causal directions in the relationships discussed. Also important is the question of cross-cultural validity of not only the instruments, but also the constructs themselves. It is clear that even though we suggested differential meanings and implications for 'what is measured by the Collective Self-Esteem Scale' from one culture to another, we have nevertheless discussed the results and compared the scores on these scales, implicitly taking for granted a certain common ground only upon which such comparisons can be deemed meaningful. It should be remembered, however, that despite the pragmatic priority given to empirical facts in this study, the epistemological question remains, and should remain, open and demanding of serious consideration. The question of validity raised with regard to self-report questionnaires, specifically the collective self-esteem scale, also merits serious consideration. The feasibility of a transparent approach becomes more clearly questionable in a case like collective self-esteem where not only personal psychological interests, but further social and political interests can become highly salient drives in a subject's presentation of self or the environment.

A number of directions might be envisioned for further work following our study. More sophisticated studies of the relationship between such notions as self, identity, and collectivity could provide a better defined basis for approaching the questions of comparability of constructs in a cross-cultural setting. Experimental designs, on the other hand, could provide clearer logical relationships between the constructs discussed here, including possible causal directions. Such research would then provide better grounds for further work on issues like transcultural validity of data, and the meanings and implications to be derived from findings such as ours. Our finding, for example, that different groups may be distinguished based on their collective self-esteem scores, can have significant political and clinical implications.

\section{REFERENCES}

[1] Ahlering, R. (2003) Collective self-esteem data from four ethnic groups.Psychological Reports, 92(2), 562-564.

[2] Ashmore, R. D., \&Jussim, L. (1997) Toward a second century of the scientific analysis of self and identity. In R. Ashmore\& L. Jussim (Eds.), Self and identity: fundamental issues (pp. 


\section{4-19). Oxford, UK: Oxford University Press.}

[3] Alund, A. (1997) The quest for identity: modern strangers and new/old ethnicites in Europe. In H. R. Wicker (Ed.), Rethinking nationalism and ethnicity: the struggle for meaning and order in Europe (pp. 91-109). New York, NY: Berg.

[4] Baldwin, J. M. (1897) Social and ethical interpretations in mental development. New York: MacMillan.

[5] Banaji, M. R., \& Prentice, D. A. (1994) The self in social contexts. Annual Review of Psychology, 45, 297-332.

[6] Bibeau, G., Chan-Yip, A. M., Lock, M., Rousseau, C., Sterlin, C., \&Fleury, H. (1992) La santé mentale et ses visages: un Québec pluriethniqe au quotidien Québec, Canada: gaëtanmorinéditeurltée.

[7] Bowler, R., Rauch, S., \&Schwarzer, R. (1986) Self-esteem and interracial attitudes in black high school students: A comparison with five other ethnic groups. Urban Education, 21, 3-19.

[8] Chang, T. (1975) The self-concept of children in ethnic groups: Black American and Korean American children. Elementary School Journal, 76, 52-58.

[9] Chodorkoff, B. (1954) Self-perception, perceptual defense, and adjustment. Journal ofbnormal and Social Psychology, 49, 508-512.

[10] Cooley, C. H. (1902) Human nature and the social order. New York, NY: Scribner.

[11] Crocker, J., Luhtanen, R, Blaine, B., \&Broadnaz, S. (1994) Collective self-esteem and psychological well-being among White, Black and Asian college students. Personality and Social Psychology Bulletin, 20, 503-513.

[12] Crocker, J., \&Luhtanen, R. (1990) Collective self-esteem and ingroup bias. Journal of Personality and Social Psychology, $58,60-67$

[13] Donnely, N. D. (1989) The changing lives of refugee Hmong women. Unpublished Ph.D. dissertation, Department of Anthropology, Univer. of Washington.

[14] Dorais, L. J. (1991) Refugee adaptation and community structure: the Indochinese in Quebec city, Canada International Migration Review, 25(3), 551-573.

[15] Fenigstein, A. (1984) Self-consciousness and the overperception of self as a target. Journal of Personality and Social Psychology, 47(4), 860-870

[16] Georgas, J., Berry, J. W., Shaw, A., \&Christakopoulou, S. (1996) Acculturation of Greek family values. Journal of cross-cultural psychology, 27(3), 329-338.

[17] Greenwald, A. G., \&Banaji, M. R. (1995) Implicit social cognition: attitudes, self-esteem, and stereotypes. Psychological Review, 102(1), 4-27.

[18] Hein, J. (1995) From Vietnam, Laos, and Cambodia : a refugee experience in the United States. New York: Twayne.

[19] Henkin, A. B., \& Nguyen, L. T. (1984) Development of self-concept among Indochinese refugee students. International Review of Modern Sociology, 14, 23-34.

[20] James, W. (1983) Principles of psychology. Cambridge, MA:
Harvard Univer. Press.

[21] Jung, C. G. (1936/1971) The relations between the ego and the unconscious. InPortable Jung (pp. 59-70). New York, NY: Penguin Books.

[22] Knight, G. P., Kagan, S., Nelson, W., \&Gumbiner, J. (1978) Acculturation of second and third generation Mexican-American children: field independence, locs of control, self-esteem, and school achievement. Journal of Cross-Cultural Psychology, 9, 87-97.

[23] Kulik, J. A., Sledge, P., \& Mahler, H. I. M. (1986) Self-confirmatory attribution, egocentrism, and the perpetuation of self-beliefs. Journal of Personality and Social Psychology, 50(3), 587-594.

[24] Long, K. M., Spears, R., \&Manstead, S. R. (1994) The influence of personal and collective self-esteem on strategies of social differentiation. British Journal of Social Psychology, $33,313-329$.

[25] Luhtanen, R., \& Crocker, J. (1992) A collective self-esteem scale: self-evaluation of one's social identity. Personality and social psychology bulletin, 18, 302-318.

[26] Markus, H., \& Herzog, A. R. (1991) The role of the self-concept in aging. Annual Review of Gerontology and Geriatrics. 11, 110-143.

[27] Markus, H., \&Wurf, E. (1987) The dynamic self-concept: a social psychological perspective. Annual Review of Psychology, 38, 299-337.

[28] Marsella, A. J., DeVos, G., \& Hsu, F. (1985) Culture and self. New York, NY: Tavistock.

[29] Mead, G. H. (1934) Mind, self, and society from the standpoint of a social behaviourist. Chicago, IL: Univer. of Chicago Press.

[30] Noh, S., Beiser, M., Hou, F., \&Kaspar, V. (1999)a Experiences of racism among Southeast Asian refugees in Canada. In R. Torh (Ed.), Psychologists facing the challenge of a global culture and human rights and mental health. Lengerich, Germany: Pabst Science. Pp. 503-515.

[31] Noh, S., Beiser, M., Kaspar, V., Hou, F., \&Rummens, E. (1999)b Perceived discrimination, depression, and coping: a study of Southeast Asian refugees in Canada. Journal of Helath Social Behavior, 40(4), 195-207.

[32] Osborne, W. L., LeGette, H. R. (1982) Sex, race, grade level, and social class differences in self-concept. Measurement and Evaluation in Guidance, 14, 195-201.

[33] Peterson, B., Ramirez, M. (1971) Real-ideal self-disparity in Negro and Mexican American children. Psychology, 8, $22-26$.

[34] Porter, J. R., \& Washington, R. E. (1979) Black identity and self-esteem: a review of studies on Black self-concept 1968-1978. Annual Review of Sociology, 5, 53-74.

[35] Porter, J. R.,Washington, R. E. (1989) Developments in research on Black identity and self-esteem: 1979-1988. Revue Internationale de PsychologieSociale, 2(3), 339-353.

[36] Porter, J. R., Washington, R. E. (1993) Minority identity and self-esteem. Annual Review of Sociology, 19, 139-161.

[37] Rahimi, S., Fisher, R. J. (2002) Collective self-esteem and 
construal of racism. Transcultural Psychiatry, 39(4), 502-516.

[38] Robins, E.M., Foster, D. (1994) Social identity versus personal identity: an investigation into the interaction of group and personal status with collective self-esteem on ingroup favouritism. South African Journal of Psychology, 24(3), 115-121.

[39] Rosenberg, M. (1965) Society and the adolescent self-image. Princeton, NJ: Princeton Univer. Press.

[40] Rosenberg, M. (1989) Society and the adolescent self-image. (Rev. ed.) Middleton, CT: Wesleyan Univer. Press.

[41] Rousseau, C., \&Drapeau, A. (1998) Parent-child agreement on refugee and children's psychiatric symptoms: a transcultural perspective. Journal of the American Academy of Child and Adolescent Psychiatry, 37(6), 629-636.

[42] Rousseau, C., \&Drapeau, A. (1999) Family trauma and its association with emotional and behavioral problems and social adjustment in adolescent Cambodian refugees. Child Abuse and Neglect, 23(12), 1263-1273.

[43] Rousseau, C., Drapeau, A, \& Platt, R. (2000) Living conditions and emotional profiles of young Cambodians, Central Americans, and Quebecois youth. Canadian Journal of Psychiatry, 45(10), 905-911.

[44] Rovner, R. A. (1981) Ethno-cultural identity and self-esteem: a reapplication of self-attitude formation theories. Human Relations, 34(5), 427-434.

[45] Rueschenberg, E. J., \&Buriel, R. (1995) Mexican American family functioning and acculturation: A family systems perspective. In A. M. Padilla (Ed.) Hispanic psychology: critical issues in theory and research. Thousand Oaks, CA: Sage.Pp. 15-25.

[46] Shedler, J., Mayman, M., \&Manis, M. (1993) The illusion of mental health. American Psychologist, 48(11), 1117-1131.
[47] Tajfel, H. (1981) Human groups and social categories: studies in social psychology. Cambridge, UK: Cambridge Univer. Press.

[48] Tajfel, H., \& Turner, J. C. (1979) An integrative theory of intergroup conflict. In W. G. Austin \& S. Worchel (Eds.), The social psychology of intergroup relations. Pacific Grove, CA: Brooks/Cole. Pp. 33-47.

[49] Tashakkori, A., \& Thompson, V. D. (1991) Race differences in self-perception and locus of control during adolescence and early adulthood: methodological implications. Genetic, Social, and General Psychology Monographs. 117, 133-152.

[50] Taylor, D. M. (1997) The quest for collective identity: the plight of disadvantaged ethnic minorities. Canadian Psychology. 38, 174-190.

[51] Verkuyten, M., \& Masson, K. (1995) 'New racism', self-esteem, and ethnic relations among minority and majority youth in the Netherlands. Social Behaviour and Personality, 23(2), 137-154.

[52] Wade, T. J., Thompson, V. D., Tashakkori, A., \&Valente, E. (1989) A longitudinal analysis of sex by race differences in predictors of adolescent self-esteem. Personality and Individual Differences, 10, 717-729.

[53] Weinberger, D. A., Schwartz, G. E., and Davidson, R. J. (1979) Low anxious, high-anxious, and repressive coping styles: psychometric patterns and behavioral and physiological responses to stress. Journal of Abnormal Psychology, 88(4), 369-380.

[54] Whittaker, E. (1993) The birth of the anthropological self and its career. Ethos, 20, 191-219.

[55] Zuckerman, M., Kernis, M. H., Guarnera, S. M., Murphy, J. F., \&Rappoport, L. (1983) The egocentric bias: seeing oneself as cause and target of others' behavior. Journal of Personality, 51(4), 621-630. 